\title{
Editorial
}

\section{Samir Dani}

Business School, Loughborough University, Leicestershire LE11 3TU, UK

E-mail: S.Dani@lboro.ac.uk

Biographical notes: Samir Dani is a Senior Lecturer in Operations Management at Loughborough University. His research domain is lean and agile systems, supply chain management and supply chain risks. He has the experience of working as a Researcher on EPSRC projects in a diverse range of management issues. He has published in refereed academic journals and presented at International conferences. He also has five years of industrial experience working as a Tool Room manager. $\mathrm{He}$ is a Member of the International Supply Chain Risk Management Network (ISCRiM).

\section{Introduction}

Since the start of the new century, the world, at large, has experienced tremendous uncertainty as a result of climate changes, epidemics, terrorist threats and increasing amount of economic upheaval. Where China is turning out to be the world's manufacturing hub and India taking over the IT domain, the users of these products and services in the supply chain have had to put in tremendous effort in order to manage the supply chains in the wake of uncertain environments. During the onslaught of Katrina, the world watched as the US government struggled to provide emergency relief and aid to the victims. In today's business environment, a supply chain is stretched out across the globe in order to provide to the customer, the product at the lowest costs and highest quality. This situation thus exposes the supply chain to a whole new set of factors as described above (external risks), which can create chaos and disruption. But this does not mean that the supply chain is devoid of any risks internally. Supplier issues, strikes, quality problems, logistics issues, etc. lead to more internal operational risks, which need a different level of mitigation. The academic work on supply chain risks has been seen on a steady increase in the past couple of years. However, now this has not been restricted only to the academic arena, but has assumed a greater focus in industry and consulting organisations. The primary aim for all this research surrounding supply chain risks is the necessity to avoid or at least reduce the impact of supply chain disruption and create a perpetually working supply chain devoid of any uncertainty. However, this is not always possible and hence, there is a need to investigate 'proactive' and 'reactive' methods to deal with supply chain uncertainties and risks.

This Special Issue aims to investigate whether the agility paradigm can provide any valuable insight into managing risks and uncertainties caused by external and internal factors in the supply chain. Some of the issues to be addressed would be to understand whether it is possible to incorporate the element of risk in strategic supply chain 
management. Do we understand all the dependencies and weak links in the supply chains? Can we create best practice for building robust and agile supply chains, which can operate in any uncertain environment? Can the agile paradigm in itself be a tool for supply chain risk mitigation?

\section{Overview of papers included in the Special Issue}

Authors were encouraged to submit papers with both theoretical and practical implications with regards to the use of agility in supply chain risk management. The papers were reviewed using a peer blind review process and seven papers have been selected for this issue. The papers range from being conceptual (at an earlier stage of the research) to an account of completed research. The papers are selected in order to provide the reader with new ideas and a practical insight into managing supply chain risks.

The first paper by Samir Dani and Rajesh Ranganathan provides an insight into developing a proactive approach to predict risks and manage uncertainties that may potentially disrupt the supply chain. This paper considers the concepts of agility and scenario planning for proactively managing risks. A conceptual model has been presented which brings together the two concepts in a process model for identifying and managing supply chain risks. The model is further described by applying it to a case depicting supply chain disruption.

The second paper by Federica Cucchiella, Massimo Gastaldi, Arunachalam Subramaniam and Tom Page presents a methodology based on the theory of real options which can be applied to protect the supply network from risks that it faces. The paper considers the increasing relevance of the supply chain on business performance. In addition, it examines the sources of uncertainty inside the supply chain. For every source of uncertainty, the associated risks are identified and links among them and real options are examined. Finally, the paper concludes with a useful framework identifying the type of possible options a firm can take in order to protect it from the risks.

The third paper by Miao Xin, Xi Bao and Hui-Min Zou studies an agility-oriented quantitative forecasting method for managing the dynamic and uncertain factors in supply chains. Some dynamic influencing factors, such as weather, temperature and date type, are quantified and taken into consideration for the agility-oriented forecasting method employing artificial neural networks. A Swarm-aided case study on the 'KFC' restaurant located in the Xidazhi Street of Harbin city, showed that the proposed method has practicality and reliability in agility-oriented forecasting.

The fourth paper by Bob Ritchie, Clare Brindley and Nick Armstrong presents a conceptual framework for the development of performance and risk management within the supply chain which is evolved from the literature and empirical evidence. Agency theory has been applied to the twin levels of dyadic performance/risk management and the management of a portfolio of performance/risks. The empirical evidence relates to the downstream management of dealerships by a large multinational organisation. Propositions are derived from the analysis relating to the issues and mechanisms that may be employed to effectively manage a portfolio of supply chain performance and risks. 
The fifth paper by Adekunle Sabitu Oyegoke, Malik M.A. Khalfan, Peter McDermott and Michael Dickinson focuses on managing risk and uncertainty in construction projects caused due to owner dissatisfaction in project outcome and dynamism. The aim of the paper is to examine the agility gap created by risk and uncertainty in the supply chain processes through procurement routes. The paper identifies some areas in supply chain processes which are prone to greater risks and uncertainty and proposes an agile management principle based on the concept of integration and fragmentation in product development and execution processes respectively, resulting in agile specialists' involvement. The paper concludes that the involvement of the agile specialists mitigates against risks and uncertainty, enhances the project quality and permits a modular approach to design that permits the use of experts' knowledge in design and construction.

The sixth paper by Omera Khan and Yvonne Cutler Greaves presents an example of how risk assessment tools helped a major UK retailer become more responsive in a global market. The purpose of the research reported here was to understand how firms mitigate supply chain risk through improved agility in the supply chain, and the actions taken to improve agility in the supply chain. This was achieved by developing a product design capability both in-house and through close collaboration with suppliers. Taking control of the design function enabled the business to enhance their agility and mitigate supply chain risks.

The seventh paper by Chee Yew Wong and Jan Stentoft Arlbjørn presents a case study to uncover how the uncertainties (supply chain, strategic and implementation) are managed in a supply chain reengineering project of a multinational toy company. Decision-making, risk (uncertainty) analysis and mitigation solution of the project are depicted in the paper along with a framework for anticipating and managing all three uncertainties and their interactions. The framework reveals how these uncertainties may be identified, analysed and mitigated.

As mentioned earlier, the contributions cover both aspects of theoretical and practical development regarding the management of supply chain risks using agility tools. It is difficult to draw precise conclusions and trends across the papers included in this Special Issue, but there is no doubt that the papers elaborate and refine many of the issues and requirements related to managing supply chain risks.

I would like to take this opportunity to thank all the authors who have submitted papers for the Special Issue and a very special thank you to all the reviewers who helped to choose the papers for this issue. 